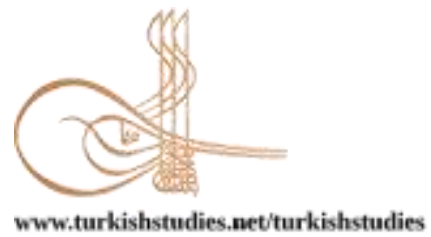

Turkish Studies

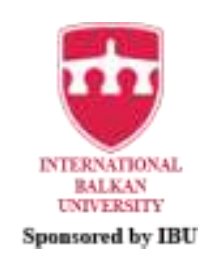

\title{
Sağlık Bilimleri Fakültesi Öğrencilerinin COVID-19 Pandemi Sürecinde Tıbbi Atık Yönetimine İlişskin Tutum ve Davranışları Üzerine Bir Değerlendirme
}

\author{
An Assessment on the Faculty of Health Sciences Students' Attitudes and Behaviours related to \\ Medical Waste Management during the COVID-19 Pandemic Process
}

Özgür Yeşilyurt* - Yalçın Dicle**

\begin{abstract}
It is required to consider that the disposal of wastes negatively affect the community health as a public health problem. In order to reduce the infection risk of the COVID-19, individuals use protective equipment such as mask, gloves, galosh etc. How these protective equipment is used is as important as how they are disposed of after use. Waste management is an issue that contributes financially to both the country's economy and institutions. In this context, the financial return of people in the field of health will be very high. In addition, effective management of waste during the pandemic period will also prevent the spread of the virus. The aim of this study is to assess the attitudes and behaviours of Faculty of Health Sciences students related to medical waste management during the COVID-19 pandemic process. Questionnaires made for this purpose were answered by 494 students online. Data collected within this scope were analysed within the context of descriptive statistics and chi square test. Ethical approval of the study was given by Muş Alparslan University Scientific Research and Publication Ethics Committee with the decision numbered 8 taken at the meeting dated 14/01/2021 and numbered 2. Students studying in health sciences deal with medical wastes both in their practical training in the hospital and while working in the hospital, and they have a potential risk due to these wastes. Healthcare professionals and students studying in health-related departments need to be more conscious about the collection and disposal of medical wastes. This study observed that third-year and fourth-year students studying at the faculty of health sciences were more careful about the medical waste management. The participants' rate of being aware of the colours of medical waste, domestic waste, and recyclable waste and hazardous waste bags is below 50\%. Approximately $85 \%$ of the students think that the COVID-19 is transmitted due to the lack of knowledge in the disposal of medical wastes such as masks, gloves and galosh. It was concluded that the awareness level of the participants on health matters, who are expected to be more conscious and show exemplary behaviours to the society, about medical waste management is not local.
\end{abstract}

\footnotetext{
* Dr. Öğr. Üyesi, Muş Alparslan Üniversitesi, Sağlık Bilimleri Fakültesi, Sosyal Hizmet Bölümü Asst. Prof. Dr., Muş Alparlsan University, Faculty of Health Sciences, Social Work Department ORCID 0000-0001-9252-3375

o.yesilyurt@alparslan.edu.tr (Sorumlu yazar)

** Dr. Öğr. Üyesi, Muş Alparslan Üniversitesi, Sağlık Bilimleri Fakültesi, Beslenme ve Diyetetik Bölümü

Asst. Prof. Dr., Muş Alparlsan University, Faculty of Health Sciences, Department of Nutrition and Dietetics ORCID 0000-0002-7658-7763

y.dicle@alparslan.edu.tr

Cite as/ Atıf: Yeşilyurt, Ö. \& Dicle, Y. (2021). Sağlık bilimleri fakültesi öğrencilerinin COVID-19 pandemi sürecinde tıbbi atık yönetimine iliş̧kin tutum ve davranışları üzerine bir değerlendirme. Turkish Studies, 16(4), 1351-1364.
} https://dx.doi.org/10.7827/TurkishStudies.51442

Received/Geliș: 19 May/Mayıs 2021

Accepted/Kabul: 25 August/Ağustos 2021

Checked by plagiarism software

Published/Yayın: 30 August/Ağustos 2021

CC BY-NC 4.0 
Structured Abstract: Wastes that negatively influence public health and the environment threaten both people and the environment. People must be conscious about waste management to leave a cleaner and more liveable environment to the next generations. In healthcare organizations, the disposal of the wastes collected, stored, and transported under the applicable law is also accomplished within the framework of the applicable law. If works and processes related to wastes are performed within the framework of legislation, then the health of people and the environment would be protected. If the applicable law is not followed, situations that threaten the health of the public and the environment might be encountered. In case of failure to comply with the applicable law, it is possible to encounter situations that threaten the health of the public and the environment. Considering the number and variety of wastes generated by healthcare organizations, it is a weighty matter to classify these wastes as domestic waste, recycling waste, medical waste, and hazardous waste. In addition, the sensitivity level to wastes directly relates to the development levels of the countries. Moreover, it is known that some developed countries buy waste from other countries, and they make an economic profit through recycling processes.

Method: The research sample consists of students of the Faculty of Health Sciences, Muş Alparslan University, who are studying in the 2020-2021 academic year and accepted to participate in the study voluntarily. Students studying at all faculties of health sciences were included in the study because of the necessity for everyone to use medical wastes due to the pandemic period. Therefore, not only students in departments related to clinics, but also all students in the faculty of health sciences were included in the study. The questionnaires created in the digital environment have been answered by 494 students.

The study was performed between January 18, 2021, and January 22, 2021, and questionnaires were collected online. Analyzes were carried out in the context of descriptive statistics and chi square test by using relevant quantitative data analysis programs. The Ethicalness of the study was obtained from the Scientific Research and Publication Ethics Committee of Muş Alparslan University (Ethics committee decision number: 2021/8) on 14/01/2021.

Results: The responses of the students studying in the Faculty of Health Sciences to the survey questions were examined. They were collected and categorized under common themes. $30.8 \%$ of the responders are male; $69.2 \%$ of them are female. Considering the distribution of the responders according to the departments, $9.3 \%$ of them continue their education and training activities in the gerontology department; $55.8 \%$ in the nursing department; $6 \%$ in the occupational health and safety department; $28.8 \%$ of them in the health management department. When evaluating in terms of the number of people living in the same house, $20.9 \%$ of the responders live in the same house with four or less than four people; $20.2 \%$ with five people; $16.6 \%$ with six people; $15.6 \%$ of them with seven people; $9.5 \%$ of them with eight people; $17.2 \%$ of them with nine people or more. $17.6 \%$ of the responders have had COVID-19 'disease; $82.4 \%$ of them did not have COVID-19 'disease. Considering the cases of having COVID-19 disease among people living in the same house, $30.2 \%$ of them have had COVID-19 'disease; 69.8\% did not have COVID-19 'disease.

We found as follows: $5.5 \%$ of the responders did not use a mask at all; $43.7 \%$ of them averagely used only one mask a day; $28.5 \%$ of them averagely used two masks a day; $10.9 \%$ of them averagely used three masks a day; $5.1 \%$ of them averagely used four masks a day; $6.3 \%$ of them averagely used five or more masks a day. When the question "At what intervals the responders change their masks" is evaluated, we found that $5.5 \%$ did not use any mask, $22.5 \%$ replaced mask between 1 and 3 hours; $24.1 \%$ of them replaced mask between 4 and 6 hours; $14.4 \%$ of them replaced mask between 7 and 9 hours; $28.3 \%$ did not replace mask all day long, and $6.3 \%$ did not change mask for days. $86.8 \%$ of the responders throw away the masks they use into the closest wastebasket; $9.9 \%$ of them take with them to throw away in the medical waste bin; $3.2 \%$ do not throw away the mask to use it over. $55.9 \%$ of the responders keep the masks they use in their bags; $6.7 \%$ of them keep the masks they used in their pockets; $9.1 \%$ keep the masks they used in their cars; $14 \%$ of them keep the masks they use inside the house; $14.4 \%$ of them do not store the mask anywhere, as they will not use it again. $85.6 \%$ of the responders think that it can infect due to the lack of knowledge about the disposal of medical waste; $14.4 \%$ of them think that it does not infect due to the lack of knowledge on the disposal of medical wastes. $47.2 \%$ of the responders think that they have enough knowledge of medical waste management. $52.8 \%$ of them think that they do not have enough knowledge of medical waste management. $34.4 \%$ of the responders stated that they took courses on medical waste management; $65.6 \%$ of responders stated that they did not take any course on medical waste management. $50 \%$ of the responders mention that they know about the classification of medical wastes; $50 \%$ of them state that they do not know about the classification of medical wastes. $9 \%$ of the responders state that they know the color of the medical disposal 
waste bags; $51 \%$ state that they do not know the color of the medical waste bags. $59.5 \%$ of the participants state that they know the biohazard symbol; $40.5 \%$ state that they do not know the biohazard symbol. $43.3 \%$ of the participants state that they know the color of the domestic waste disposal bag; $56.7 \%$ of them stated that they do not know the color of the household waste bag. $48.4 \%$ of the participants state that they know the color of the medical waste bag; $51.6 \%$ of them stated that they do not know the color of the medical waste bag. $45.1 \%$ of the responders state that they know the color of the recycling waste bag; $54.8 \%$ of them state that they do not know the color of the recycling disposal waste bag. $22.3 \%$ of the responders mention that they know the color of the hazardous waste bag; $77.7 \%$ of them state that they do not know the color of the hazardous waste bag.

Conclusion: It was concluded that the healthcare candidates, who are expected to be more conscious about medical waste and display exemplary behavior in society, have enough knowledge on medical waste management. Therefore, it is required to overemphasize medical waste management in the related courses to increase the knowledge level of the students who are candidates for healthcare professionals who will take active roles in the hospital about medical waste management. It will positively affect the knowledge, attitude, and behavior of students regarding medical waste management. This study investigated the knowledge levels of health sciences students on medical waste management. And it was suggested for future studies to reveal whether there is a significant difference by repeating the study in similar samples in later periods by providing relevant training.

Keywords: Medical waste management, COVID-19, Faculty of Health Sciences students, attitude, behaviour

Öz: Toplum sağlığını olumsuz etkileyen atıkların bertaraf edilmesi bir halk sağlığı sorunu olarak değerlendirilmesi gerekmektedir. COVID-19 bulaş riskinin azaltılması için bireyler maske, eldiven, galoş gibi koruyucu ekipmanları kullanmaktadır. Bu koruyucu ekipmanların nasıl kullanıldığının önemli olduğu kadar kullanıldıktan sonra nasıl bertaraf edildiği konusu da önem arz etmektedir. Atık yönetimi hem ülke ekonomisine hem de kurumlara mali katkısı bulunan bir konudur. Bu bağlamda sağlık alanındaki kişilerin dikkatli olmasının mali getirisi oldukça yüksek olacaktır. Buna ek olarak pandemi döneminde atıkların etkin bir şekilde yönetilmesi virüsün yayılmasını da engellenebilecektir. Sağlık Bilimleri Fakültesi öğrencilerinin COVID-19 pandemi sürecinde tıbbi atık yönetimine ilişkin tutum ve davranışlarının değerlendirmesi bu çalışmanın amacını oluşturmaktadır. Bu amaçla oluşturulmuş olan anketler çevrimiçi olarak 494 öğrenci tarafından cevaplandırılmıştır. Bu kapsamda toplanmış olan verilerin tanımlayıcı istatistikler ve ki kare bağlamında analizleri yapılmıştır. Bu çalışmanın etik onayı Muş Alparslan Üniversitesi Bilimsel Araştırma ve Yayın Etiği Kurulu tarafından 14/01/2021 tarihli ve 2 sayılı toplantısında alınan 8 numaralı kararınca verilmiştir. Sağlık bilimlerinde eğitim gören öğrenciler hem hastanedeki uygulama eğitimlerinde hem de hastanede çalışırken tıbbi atıklarla uğraşmakta ve bu atıklardan kaynaklı olarak potansiyel risk taşımaktadırlar. Tıbbi atıkların toplaması ve bertaraf edilmesinde sağlık çalışanlarının ve sağlıkla ilgili bölümlerde eğitim öğretim gören öğrencilerin daha bilinçli olmaları gerekmektedir. Bu çalışmada sağlık bilimleri fakültesinde eğitim gören üçüncü ve dördüncü sınıf öğrencilerin tıbbi atık yönetimi konularında daha dikkatli oldukları gözlemlenmiştir. Katılımcıların tıbbi atık, evsel atık, geri dönüşüm atık ve tehlikeli atık torbalarının renklerini bilme oranları \%50'nin altında çıkmıştır. Ayrıca öğrencilerin yaklaşık \%85'i COVID-19'un kullanılan maske, eldiven, galoş gibi tıbbi atıkların bertaraf edilmesindeki bilgi eksikliği sebebiyle bulaştığını düşünmektedirler. Sağlık konularında daha bilinçli olmaları ve topluma örnek davranışlar sergilemeleri beklenen katılımcıların tıbbi atık yönetimi ile ilgili bilgi düzeylerinin yeterli olmadığı sonucuna varılmıştır.

Anahtar Kelimeler: Tıbbi atık yönetimi, COVID-19, Sağlık Bilimleri Fakültesi öğrencileri, tutum, davranış

\section{Giriş}

Halk sağlığını ve çevreyi olumsuz etkileyen atıklar hem insanları hem de çevreyi tehdit etmektedir. Atık yönetimi konusunda insanların bilinçli olması sonraki nesillere temiz ve daha yaşanabilir bir çevre bırakmak adına önem arz etmektedir.

Sağlık kuruluşlarında ilgili mevzuatlara göre toplanıp depolanarak taşınan atıkların bertaraf edilmesi konusu da ilgili mevzuat çerçevesinde yapılmaktadır. Atıklarla ilgili iş ve işlemler 
mevzuatlar çerçevesinde yapıldığında insanların ve çevrenin sağlığı korunmaktadır. İlgili mevzuatlara uyulmadığ durumlarda halkın sağlığını ve çevreyi tehdit eden durumlarla karşı karşıya kalınabilmektedir.

Sağlık kurumlarında ortaya çıkan atıkların sayısı ve çeşitliliği göz önünde bulundurulduğunda bu atıkların evsel atık, geri dönüşüm atık, tıbbi atık ve tehlikeli atık şeklinde sınıflandırılması önemli bir konudur. Ayrıca atıklara hassasiyet düzeyi ülkelerin gelişmişlik düzeyleri ile de doğrudan ilgilidir. Hatta bazı gelişmiş ülkeler diğer ülkelerden atık satın alma yoluna giderek geri dönüşün süreçleriyle ekonomik anlamda bir kazanç sağladıkları bilinmektedir.

COVID-19 pandemisinde, yatan hasta sayıları ve özellikle buz dağının görünmeyen yüzü olan belirti göstermeyen hasta sayıları düşünüldügünnde enfekte ve kontamine atık miktarının oldukça fazla olduğu açıkça görülmektedir. Atık miktarının fazla oluşu atık yönetiminin önemini daha da artırmaktadır.

Kontamine maskeler, eldivenler, son kullanma tarihi geçmiş veya kullanılmış ilaçlar evsel atıklara kolaylıkla karışabileceği için tehlikeli atık olarak değerlendirilmeli ve diğer atıklardan ayrı işlemlere tabi tutulmalıdırlar. Bunlar ayrı olarak depolanıp toplanmalıdır. Bu tür atıkların geri dönüşümleri ve bertarafları ilgili kılavuzlar ve mevzuat çerçevesinde gerçekleştirilmelidir (UNEP UN Environment Programme, Waste management an essential public service in the fight to beat COVID-19, Erişim Tarihi: 24 Ocak 2021, http://www.unep.org/news-and-stories/pressrelease/waste-management-essential-public-service-fight-beat-covid-19). Örneğin COVID-19 pandemisinden en çok etkilenen şehirler arasında yer alan Wuhan şehri, atıkları güvenli bir şekilde atmak için mücadele etmektedir. Diğer bir ifadeyle COVID-19 Çin'i tıbbi atık yığınlarıyla baş başa bırakmıştır. Wuhan şehrinde normal döneme kıyasla altı kat daha fazla tıbbi atık üretildiği ifade edilmektedir (Coronavirus leaves China with mountains of medical waste, Erişim Tarihi: 24 Ocak 2021, https://www.scmp.com/news/china/society/article/3074722/coronavirus-leaves-chinamountains-medical-waste).

Tıbbi atıklar pandemi döneminden önce genel olarak değerlendirildiğinde özellikle tedavi hizmeti veren kurum ve kuruluşlarda üretilmekteydi. COVID -19 pandemi döneminde tıbbi atık miktarı artmış ve atığın bulunma çerçevesi genişlemiştir. COVID -19 pandemisinin yaylımını döneminde salgının yayılımını azaltmak amacıyla insanların kullanmış oldukları koruyucu ekipmanlar (maske, eldiven, siperlik gibi) kullanıldıktan sonra tıbbi atıklar olarak değerlendirmeli, evsel atıklarla beraber atılmamalı, ayrı olarak toplanıp depolanmalı ve bertaraf işlemleri tıbbi atığa göre yapılmalıdır. Kontamine olmuş atıkların dikkatsizce toplanıp depolanarak bertaraf edilmesi virüsün yayılım hızını artıracağı unutulmamalıdır. Ayrıca koruyucu ekipmanları bireylerin çok uzun süre kullanmamaları belirli periyotlarda değiştirmemelerinin de virüsün yayılımını artırma durumu vardir.

Mevcut bilimsel çalışmalarda COVID-19'un atıklar vasıtasıyla bulaştığına dair kesin bir kanıt mevcut değilse de atık çalışanlarını ve genel olarak toplum sağlığını korumak adına tüm prosedürel önlemlerin alınması gerekmektedir (COVID-19 Pandemisinde Atık Yönetimi. Erişim Tarihi: 25 Ocak 2021, https://korona.hasuder.org.tr/covid-19-pandemisinde-atik-yonetimi/). Ayrıca her bireyin bu konuda eşit oranda sorumlu olduğu düşünülürse, toplumun geneli temel tıbbi atık yönetimi hakkında bilinçlendirilmelidir. Akbolat, Işık, Dede ve Çimen (2011) sağlık çalışanlarının mevzuat bilgisinin yeterli olması atık yönetim sürecinin başarısını olumlu etkileyeceği ve atıkların geri dönüştürülmesi yoluyla ülke ekonomisine ciddi anlamda katkı sağlanacağını unutulmamalıdır. COVID-19 Salgın Yönetimi ve Çalışma Rehberi’nde (2021: 268) kişisel koruyucu ekipmanların çift poşetlenerek evsel atıklara atılması gerektiği belirtilmiştir. Atık yönetimi ile ilgili yapılacak iş ve işlemlerde Sağlık Bakanlığı direktiflerine ve ilgili mevzuata uyularak hareket edilmesi gerektiği vurgulanmıştır. 
Çalışmada sağlıkçı kimliği taşıması nedeniyle gerek çekirdek ailesi içinde gerekse daha geniş sayılan yakın çevresi tarafından kendilerine biçilen sağlık danışmanlığı rolleriyle sağlık bilimleri fakültesi öğrencilerinin özellikle tıbbi atık miktarının fazla olduğu COVID-19 pandemisi döneminde tıbbi atık yönetimine ilişkin bilgi ve tutumlarının değerlendirilmesi amaçlanmaktadır. Buna ek olarak atık yönetimi ile ilgili farkındalıklarını geliştirmeleri adına sonraki dönemlerde atık yönetimi ile ilgili eğitimler verilmesine ve tıbbi atık yönetimi konularının işlendiği derslerin sağlıkçıların yetiştirilmesi için oluşturulan müfredata eklenmesinin ne kadar ne kadar ihtiyaç olduğu sorusuna da cevap bulunmuş olacaktır.

\section{Literatür Taraması}

Sağlık çalışanlarının ve sağlık alanında eğitim gören öğrencilerin tıbbi atık yönetimi konusunda tutum, davranış ve bilgi düzeylerini ortaya koymak amaciyla literatürde yer alan bazı çalışmalara aşağıda yer verilmiştir.

Köseoğlu, Toptan ve Altındiş (2019: 245) diş hekimlerinin tıbbi atık yönetimi ile ilgili bilgi, tutum ve davranışlarını ölçmek amacıyla yapmış oldukları çalışmada diş hekimlerinin (86 kişi) \%68,21'inin tıbbi atıkları atarken torbanın renklerine dikkat ettikleri; \%71,77'sinin çalıştıkları kurumlarda atıkları ayrı ayrı torbalara attıkları; \%70,61'inin tıbbi atık yönetimi ile ilgili eğitim aldıkları; \%81,23'ünün biyotehlike simgesini bildikleri tespit edilmiştir. Çalışma sonucunda diş hekimlerine tıbbi atık mevzuatıyla ilgili eğitimler verilmesinin hekimlerin bilgi, tutum ve davranışlarını olumlu etkilediği sonucuna varılmıştır.

Turan, Özdemir Aydın, Kaya, Atabek Aştı, Aksel ve Yılmaz (2019: 19) hemşirelik öğrencilerinin tıbbi atık yönetimini belirlemek için yaptıkları çalışmada; tıbbi atıkla ilgili eğitim almış olan öğrencilerin tıbbi atıkların toplanması ve muhafaza edilmesi ile ilgili oldukça bilgi sahibi olduklar ve tınbbi atık toplama torba renlerni bildikleri sonucuna varılmıştır. Çalışmada dikkat çekilen diğer bir konu da alınan eğitim sayısı kadar verilen eğitimin çeşitliliği konusudur.

Doğan ve Aktaş (2017: 98) hemşirelik öğrencilerinin tıbbi atık yönetimini belirlemek için yaptıkları çalışmada; hemşirelik öğrencilerinin bilgi düzeylerinin orta seviyede olduğu sonucuna varmışlardır. Ayrıca öğrencilerin eğitim düzeyleri arttıkça bilgi düzeylerinin azalması durumunu vurgulamışlardır. Öğrencilerin tıbbi atık yönetimi ile ilgili derler almalarına rağmen atık konusunda uygulamada eksikliklerinin olduğu bu çalışmada ifade edilmiştir. Uygulama eksikliğini ise alınan eğitim ile klinik çalışmalarının entegrasyonundaki eksiklikten kaynaklandığını ifade etmişlerdir.

Terzi ve Yüce'nin (2017: 58) stajyer öğrencilerin tıbbi atık yönetimi ile ilgili bilgi düzeylerinin değerlendirilmesi amacıyla sağlık hizmetleri meslek yüksekokulu son sınıf öğrencileri ile yapmış oldukları çalışmada öğrencilerin \%70,7'sinin tıbbi atık yönetimi ile ilgili bir ders aldıkları; \%65,8'inin tıbbi atık tanımını bildikleri; \%39,8'inin tıbbi atık sınıflandırmasını bildikleri; \%79'unun tıbbi atık toplama torbalarının renklerini bildikleri tespit edilmiştir. Çalışmada sorulara verilen yanıtlardaki yüzdeler yüksek olsa da öğrencilerin bilgi düzeylerinin yeterli olmadığı ifade edilmiştir.

Malini ve Eshwar'ın (2015: 172) Hindistan ve gelişmekte olan ülkeler bağlamında tıbbı atık yönetimi ile ilgili eksiklikleri tespit etmek ve düzenlemeler yapmak amacıyla yapmış oldukları çalışmada sağlık çalışanlarının (337 kişi) tıbbi atık bilgileri ölçülmeye çalışılmıştır. Hemşirelerin yarıdan azının atıkların renk kodlarını bildiği; doktor ve hemşirelerin \%50'sinin laboratuvar teknisyenlerinin ise \%26'sının tıbbi atık yönetimi ile ilgili eğitime sahip oldukları ortaya çıkmıştır. Bazı çalışanların ise hiç eğitim almadığı gözlemlenmiştir. $\mathrm{Bu}$ çalışma sonucunda sağlık çalışanlarına atık yönetimi ile ilgili derslerin verilmesi gerektiği ve yönetimin atık kurallarına uyması adına protokoller yapması gerektiği sonucuna varılmıştır.

Jadhav, Thangaraj, Dsouza ve Rao'nun (2015: 726) bir eğitim müdahalesi öncesinde ve sonrasında hemşirelik öğrencilerinin tıbbi atıkların işlenmesi ile ilgili bilgi, tutum ve uygulama 
durumlarının değerlendirilmesi amacıyla yapmış oldukları çalışmada hemşirelerin iyi eğitim aldıklarında atıklarla ilgili daha bilinçli davrandıklarını vurgulamışlardır. Ayrıca hemşirelik öğrencilerinin (154 kişi) eğitim düzeyleri arttıkça almış oldukları eğitimler tıbbi atıklarla ilgili bilgi, tutum ve uygulamalarında iyileşmelere sebep olduğunu bildirmişlerdir.

Ujwala U, Ramasankaram, Satyanarayan, Appajirao, Kulkarni'nin (2012: 428) tıp ve hemşirelik öğrencilerinin (113 kişi) tıbbı atık yönetimi ile ilgili farkındalıklarını ortaya koymak adına yapmış oldukları çalışmada; katılımcıların çoğu atıkların ayrıştırılmasında renk kodlarının ne olması gerektiğini bilmektedirler. Tıbbi atıkların hangi torbalara konulması gerektiği ile ilgili sorulara neredeyse yarısı doğru cevap vermiştir.

Mathur, Dwivedi, Hassan ve Misra'nın (2011: 143) sağlık bakımı esnasında ortaya çıkan atıkların diğer atıklardan daha fazla enfeksiyona ve yaralanmaya neden olduğunu vurguladıkları çalışmalarında sağlık çalışanlarının (283 kişi) tıbbı atık yönetimi ile ilgili bilgi, tutum ve uygulama durumlarını değerlendirmişlerdir. Doktor, hemşire ve laboratuvar teknisyenleri tıbbi atık yönetimi konusunda temizlik personele nispeten daha fazla bilgiye sahip oldukları sonucuna varılmıştır. Buna ek olarak renk kodlaması ve atıkların ayrıştırılması konularında da hemşireler ve laboratuvar personelinin doktorlara nispeten daha iyi oldukları tespit edilmiştir. Buna ek olarak atıklarla ilgili temizlik personelin eğitime ihtiyacı bulunduğu da tespit edilmiştir.

Akbolat, Işık, Dede ve Çimen'in (2011: 131) tıbbi atıklar konusunda sağlık çalışamlarının eğitim duurmlarını ve tıbbi atıklarla ilgili belirğin özelliklerini ortaya koymak için yapmış oldukları tanımlatıcı çalışmada, tıbbi atıkların tasnifi ile ilgili sağlık çalışanlarının \%81,5'inin bilgi sahibi olduğu görülmiştür. Çalışma sonucunda tıbbi atıklarla ilgi mevzuat ve eğitimlere ağırlık verilemsinin hem kuruma hem de ülke ekonomisine katkı sağlayacağı vurgulanmıştır.

\section{Yöntem}

Araştırmanın örneklemini 2020-2021 eğitim-öğretim y1lında öğrenim gören ve araştırmaya gönüllü olarak katılmayı kabul eden Muş Alparslan Üniversitesi Sağlık Bilimleri Fakültesi öğrencileri oluşturmaktadır. Pandemi döneminde olunması sebebiyle koruyucu tıbbi malzemeleri herkes tarafından kullanılmasından dolayı tüm sağlık bilimleri fakültesinde öğrenim gören öğrenciler çalışmaya dahil edilmiştir.

Özellikle COVID-19 pandemi sürecinde sağlıklı veya hasta her bireyin koruyucu ekipman kullanım zorunluluğu sebebiyle sadece kliniklerde atıklar üretilmemekte neredeyse her yerde bu atıklara rastlanmaktadır. Bu sebeple sadece sağlık profesyoneli adaylarının kliniğe bakan bölümlerine değil, tüm sağlık bilimleri fakültesinde öğrenim gören öğrenciler (832 öğrenci) bu çalışmaya dahil edilmiştir. Dijital ortamda oluşturulmuş olan anketler 494 öğrenci tarafindan cevaplanmışırı.

Çalışma 18 Ocak 2021 - 22 Ocak 2021 tarihleri arasında gerçekleştirilmiş olup anketler çevrimiçi olarak yapılmış ve veriler toplanmıştır. Çalışma ilgili nicel veri analiz programları vasıtasıyla tanımlayıcı istatistikler ve ki kare bağlamında analizler yapılmıştır. Bu çalışmanın etik onay1 Muş Alparslan Üniversitesi Bilimsel Araştırma ve Yayın Etiğgi Kurulu tarafından 14/01/2021 tarihli ve 2 sayılı toplantısında alınan 8 numaralı kararınca verilmiştir.

\section{Bulgular}

Araştırmaya katılan Sağlık Bilimleri Fakültesi öğrencilerin anket sorularına verdikleri yanıtlar incelenmiş; cevaplar ortak temalar altında toplanıp kategorileştirilmiştir.

Tablo 1'de katılımcıların demografik özelliklerine ve COVID-19'a yakalanma durumlarına yer verilmiştir. 
Tablo 1: Katılımcıların Demografik Özelliklerine ve COVID-19'a Yakalanma Hastalığı Geçirme Durumlar1

\begin{tabular}{|c|c|c|c|}
\hline Iffadeler & Grup & Sayı (n) & Yüzde $(\%)$ \\
\hline \multirow{3}{*}{ Cinsiyet } & Erkek & 152 & 30,8 \\
\hline & Kadın & 342 & 69,2 \\
\hline & Toplam & 494 & 100,0 \\
\hline \multirow{5}{*}{ Bölüm } & Gerontoloji & 46 & 9,3 \\
\hline & Hemşirelik & 276 & 55,8 \\
\hline & İş Sağlığı ve Güvenliği & 30 & 6,0 \\
\hline & Sağlık Yönetimi & 142 & 28,8 \\
\hline & Toplam & 494 & 100,0 \\
\hline \multirow{7}{*}{ Aynı evde yaşayan kişi sayısı } & 4 kişi ve altı & 103 & 20,9 \\
\hline & 5 kişi & 100 & 20,2 \\
\hline & 6 kişi & 82 & 16,6 \\
\hline & 7 kişi & 77 & 15,6 \\
\hline & 8 kişi & 47 & 9,5 \\
\hline & 9 kişi ve üzeri & 85 & 17,2 \\
\hline & Toplam & 494 & 100,0 \\
\hline \multirow{3}{*}{ COVID-19 geçirme durumu } & Evet & 87 & 17,6 \\
\hline & Hayır & 407 & 82,4 \\
\hline & Toplam & 494 & 100 \\
\hline \multirow{3}{*}{$\begin{array}{l}\text { Aynı evde yaşayan kişilerden } \\
\text { COVID-19 geçirme durumu }\end{array}$} & Evet & 149 & 30,2 \\
\hline & Hayır & 345 & 69,8 \\
\hline & Toplam & 494 & 100,0 \\
\hline
\end{tabular}

Tablo 1'e göre katılımcıların \%30,8'i erkekler; \%69,2'si ise kadınlar oluşturmaktadır. Katılımcıların bölümlere göre dağılımlarına bakıldığında $\% 9,3$ 'ü gerontoloji bölümünde; $\% 55,8$ 'i hemşirelik bölümünde; \%6'sı iş sağlığı ve güvenliği bölümünde; \%28,8'i ise sağl1k yönetimi bölümünde eğitim ve öğretim faaliyetlerine devam etmektedir. Aynı evde yaşayan kişi sayısı açısından değerlendiğinde katılımcıların \%20,9'u 4 veya 4'ten az kişiyle; \%20,2'si 5 kişiyle; \%16,6's1 6 kişiyle; \%15,6's1 7 kişiyle; \%9,5'i 8 kişiyle; \%17,2'si 9 kişi ve üzeri kişiyle sayıda kişiyle aynı yaşamaktadırlar. Katılımcıların \%17,6'sı COVID-19' hastalığını geçirmiş; \%82,4'ü ise COVID-19' hastalığını geçirmemiştir. Aynı evde yaşayan kişilerden COVID-19 hastalığını geçirme durumuna bakıldığında \%30,2'si COVID-19' hastalığını geçirmiş; \%69,8'i ise COVID19' hastalığını geçirmemiştir.

Tablo 2'de katılımcıların maske kullanımı ile ilgili tutum ve davranışlarına yer verilmiştir. 
Tablo 2: Katılımcıların Maske Kullanımı ile İlgili Tutum ve Davranışları

\begin{tabular}{|c|c|c|c|}
\hline İfadeler & Grup & Sayı (n) & Yüzde (\%) \\
\hline \multirow{7}{*}{$\begin{array}{l}\text { Kullanılan } \\
\text { günlük } \\
\text { ortalama } \\
\text { maske adedi }\end{array}$} & 0 adet & 27 & 5,5 \\
\hline & 1 adet & 216 & 43,7 \\
\hline & 2 adet & 141 & 28,5 \\
\hline & 3 adet & 54 & 10,9 \\
\hline & 4 adet & 25 & 5,1 \\
\hline & 5 ve üzeri adet & 31 & 6,3 \\
\hline & Toplam & 494 & 100,0 \\
\hline \multirow{7}{*}{$\begin{array}{l}\text { Hangi } \\
\text { aralıklarla } \\
\text { maske } \\
\text { değiştirildiği }\end{array}$} & Maske kullanmiyorum. & 27 & 5,5 \\
\hline & 1-3 saat arasında değiştiriyorum. & 111 & 22,5 \\
\hline & 4-6 saat arasında değiştiriyorum. & 119 & 24,1 \\
\hline & 7-9 saat arasında değiştiriyorum. & 71 & 14,4 \\
\hline & Gün boyu değiştirmem. & 140 & 28,3 \\
\hline & Günlerce değiştirmem. & 26 & 5,3 \\
\hline & Toplam & 494 & 100,0 \\
\hline \multirow{4}{*}{$\begin{array}{c}\text { Maskenin } \\
\text { nereye atıldığ }\end{array}$} & En yakın çöp kutusuna atıyorum. & 429 & 86,8 \\
\hline & $\begin{array}{l}\text { Tibbi atık kutusuna atmak üzere yanımda } \\
\text { taşıyorum. }\end{array}$ & 49 & 9,9 \\
\hline & $\begin{array}{l}\text { Kullandığım maskeyi tekrar kullanmayı } \\
\text { düşündüğüm için atmıyorum. }\end{array}$ & 16 & 3,2 \\
\hline & Toplam & 494 & 100,0 \\
\hline \multirow{6}{*}{$\begin{array}{c}\text { Kullanılmış } \\
\text { maskenin } \\
\text { nerede } \\
\text { muhafaza } \\
\text { edildiği }\end{array}$} & Çantada muhafaza ediyorum. & 276 & 55,9 \\
\hline & Cepte muhafaza ediyorum. & 33 & 6,7 \\
\hline & Arabada muhafaza ediyorum. & 45 & 9,1 \\
\hline & Evin içerisinde muhafaza ediyorum. & 69 & 14,0 \\
\hline & $\begin{array}{l}\text { Kullandığım maskeyi tekrar } \\
\text { kullanmayacağım için herhangi bir yerde } \\
\text { muhafaza etmiyorum. }\end{array}$ & 71 & 14,4 \\
\hline & Toplam & 494 & 100,0 \\
\hline
\end{tabular}

Tablo 2'ye göre kat1lımcıların \%5,5'inin hiç maske kullanmadı̆̆ı; \%43,7'si günde ortalama 1 adet maske kullandığı; \%28,5'i günde ortalama 2 adet maske kullandığı; \%10,9'u günde ortalama 3 adet maske kullandığg; $\% 5,1$ 'inin günde ortalama 4 adet maske kullandığı; $\% 6,3$ 'ünün günde ortalama 5 ve üzeri adet maske kullandığı tespit edilmiştir. Katılımcıların hangi aralıklarla maske değiştirdiği sorusu değerlendirildiğinde \%5,5'inin maske kullanmadığı, \%22,5'inin 1-3 saat arasında maske değiștirdiği; \%24,1'inin 4-6 saat arasında maske değiștirdiği; \%14,4'ünün 7-9 saat arasında maske değiștirdiği; \%28,3'ünün gün boyu maske değiștirmediği ve \%6,3'ünün ise günlerce maske değiştirmediği tespit edilmiştir. Katılımcıların \%86,8'i kullandıkları maskeleri en yakın çöp kutusuna atmakta; \%9,9'u tıbbi atık kutusuna atmak amacıyla yanında taşımakta; \%3,2'si ise kullandığı maskeyi tekrar kullanmak için atmamaktadır. Katılımcıların \%55,9'u kullanmış oldukları maskeleri çantalarında muhafaza etmekte; \%6,7'si kullanmış oldukları maskeleri ceplerinde muhafaza etmekte; \%9,1'i kullanmış oldukları maskeleri arabalarında muhafaza etmekte; \%14'ü kullanmış oldukları maskeleri evin içerisinde muhafaza etmekte; \%14,4'ü kullandığı maskeyi tekrar kullanmayacağı için herhangi bir yerde muhafaza etmemektedir.

Tablo 3 ’te katılımcıların tıbbi atık yönetimi ile ilgili bilgi düzeylerine yer verilmiştir. 
Tablo 3: Katılımcıların Tıbbi Atık Yönetimi ile İlgili Bilgi Düzeyleri

\begin{tabular}{|c|c|c|c|}
\hline İfadeler & Grup & Sayı (n) & Yüzde (\%) \\
\hline \multirow{3}{*}{$\begin{array}{l}\text { COVID-19'un maske, eldiven, } \\
\text { galoş gibi tıbbi atıkların bertaraf } \\
\text { edilmesindeki bilgi eksikliği } \\
\text { sebebiyle bulaştığını düşünüyor } \\
\text { musunuz? }\end{array}$} & Evet & 423 & 85,6 \\
\hline & Hayır & 71 & 14,4 \\
\hline & Toplam & 494 & 100,0 \\
\hline \multirow{3}{*}{$\begin{array}{c}\text { Tıbbi atık yönetimiyle ilgili yeterli } \\
\text { düzeyde bilgi sahibi olduğunuzu } \\
\text { düşünüyor musunuz? }\end{array}$} & Evet & 233 & 47,2 \\
\hline & Hayır & 261 & 52,8 \\
\hline & Toplam & 494 & 100,0 \\
\hline \multirow{3}{*}{$\begin{array}{l}\text { Tıbbi atık yönetimiyle ilgili } \\
\text { herhangi bir ders aldınız mı? }\end{array}$} & Evet & 170 & 34,4 \\
\hline & Hayır & 324 & 65,6 \\
\hline & Toplam & 494 & 100,0 \\
\hline \multirow{3}{*}{$\begin{array}{c}\text { Tibbi atıkların sınıflandırmasını } \\
\text { biliyor musunuz? }\end{array}$} & Evet & 247 & 50,00 \\
\hline & Hayır & 247 & 50,00 \\
\hline & Toplam & 494 & 100,0 \\
\hline \multirow{3}{*}{$\begin{array}{l}\text { Tibbi atık toplama torbalarının } \\
\text { renklerini biliyor musunuz? }\end{array}$} & Evet & 242 & 49,0 \\
\hline & Hayır & 252 & 51,0 \\
\hline & Toplam & 494 & 100,0 \\
\hline \multirow{3}{*}{ Biyotehlike simgesini } & Bilen & 294 & 59,05 \\
\hline & Bilmeyen & 200 & 40,05 \\
\hline & Toplam & 494 & 100,0 \\
\hline \multirow{3}{*}{ Evsel atık torbasının rengini } & Bilen & 214 & 43,3 \\
\hline & Bilmeyen & 280 & 56,7 \\
\hline & Toplam & 494 & 100,0 \\
\hline \multirow{3}{*}{ Tıbbi atık torbasının rengini } & Bilen & 239 & 48,4 \\
\hline & Bilmeyen & 255 & 51,6 \\
\hline & Toplam & 494 & 100,0 \\
\hline \multirow{3}{*}{$\begin{array}{c}\text { Geri dönüşüm atık torbasının } \\
\text { rengini }\end{array}$} & Bilen & 223 & 45,1 \\
\hline & Bilmeyen & 271 & 54,8 \\
\hline & Toplam & 494 & 100,0 \\
\hline \multirow{3}{*}{ Tehlikeli atık torbasının rengini } & Bilen & 110 & 22,3 \\
\hline & Bilmeyen & 384 & 77,7 \\
\hline & Toplam & 494 & 100,0 \\
\hline
\end{tabular}

Tablo 3'e göre katılımcıların \%85,6's1 tıbbi atıkların bertaraf edilmesi konusundaki bilgi eksikliğinden bulaşabileceğini düşünmekte; \%14,4'ü ise tıbbi atıkların bertaraf edilmesi konusundaki bilgi eksikliğinden bulaşmadığını düşünmektedir. Katılımcıların \%47,2'si tıbbi atık yönetimiyle ilgili yeterli düzeyde bilgi sahibi olduğunu düşünmekte; $\% 52,8$ 'i ise tıbbi atık yönetimiyle ilgili yeterli düzeyde bilgi sahibi olmadığını düşünmektedir. Katılımcıların \%34,4'ü tıbbi atık yönetimiyle ilgili ders aldığını belirtmekte; \%65,6'sı ise tıbbi atık yönetimiyle ilgili ders almadığını belirtmektedir. Katılımcıların \%50'si tıbbi atıkların sınıflandırmasını bildiğini belirtmekte; \%50'si ise tıbbi atıkların sınıflandırmasını bilmediğini belirtmektedir. Katılımcıların 
\%49'u tıbbi atık torbalarının rengini bildiğini belirtmekte; \%51'i ise tıbbi atık torbalarının rengini bilmediğini belirtmektedir. Katılımc1ların \%59,5'i biyotehlike simgesini bildiğini belirtmekte; $\% 40,5$ 'i ise biyotehlike simgesini bilmediğini belirtmektedir. Katılımcıların \%43,3'ü evsel atık torbasının rengini bildiğini belirtmekte; \%56,7'sinin ise evsel atık torbasının rengini bilmediğini belirtmektedir. Katılımcılar \%48,4'ünün tıbbi atık torbasının rengini bildiğini belirtmekte; $\% 51,6$ 'sının ise tıbbi atık torbasının rengini bilmediğini belirtmektedir. Katılımcılar \%45,1'inin geri dönüşüm atık torbasının rengini bildiğini belirtmekte; $\% 54,8$ 'inin ise geri dönüşüm atık torbasının rengini bilmediğini belirtmektedir. Katılımcılar \%22,3'ünün tehlikeli atık torbasının rengini bildiğini belirtmekte; \%77,7'sinin ise tehlikeli atık torbasının rengini bilmediğini belirtmektedir.

Tablo 4: Tek Örneklem Ki Kare Testi Sonuçları

\begin{tabular}{|c|c|c|c|c|c|c|}
\hline Sorular & $\begin{array}{c}1 . \\
\text { Sinif }\end{array}$ & $\begin{array}{c}2 . \\
\text { Sinıf }\end{array}$ & $\begin{array}{c}3 . \\
\text { Sinif }\end{array}$ & $\begin{array}{c}4 . \\
\text { Sinif }\end{array}$ & Toplam & $\begin{array}{c}\text { Ki kare ve } \\
\text { p değeri }\end{array}$ \\
\hline $\begin{array}{l}\text { Tıbbi atık yönetimiyle ilgili yeterli düzeyde } \\
\text { bilgi sahibi olduğunuzu düşünüyor } \\
\text { musunuz? }\end{array}$ & 89 & 38 & 49 & 57 & 233 & $\begin{array}{l}\chi_{(0,05 ; s d=3)}^{2} \\
=14,161 \\
p=0,003\end{array}$ \\
\hline $\begin{array}{l}\text { Tıbbi atıkların sınıflandırmasını biliyor } \\
\text { musunuz? }\end{array}$ & 75 & 46 & 58 & 68 & 247 & $\begin{array}{l}\chi_{(0,05 ; s d=3)}^{2} \\
=30,254 \\
p=0,000\end{array}$ \\
\hline $\begin{array}{l}\text { Tibbi atık toplama torbalarının renklerini } \\
\text { biliyor musunuz? }\end{array}$ & 71 & 52 & 55 & 64 & 242 & $\begin{array}{l}\chi_{(0,05 ; s d=3)}^{2} \\
\quad=5,184 \\
p=0,000\end{array}$ \\
\hline Biyotehlike simgesini bilme durumu & 110 & 64 & 66 & 54 & 294 & $\begin{array}{l}\chi_{(0,05 ; s d=3)}^{2} \\
\quad=5,222 \\
p=0,156\end{array}$ \\
\hline Evsel atık torbasının rengini bilme durumu & 71 & 44 & 44 & 55 & 214 & $\begin{array}{l}\chi_{(0,05 ; s d=3)}^{2} \\
=14,829 \\
p=0,002\end{array}$ \\
\hline Tibbi atık torbasının rengini bilme durumu & 71 & 50 & 52 & 66 & 239 & $\begin{array}{l}\chi_{(0,05 ; s d=3)}^{2} \\
=26,764 \\
p=0,000\end{array}$ \\
\hline $\begin{array}{l}\text { Geri dönüşüm atık torbasının rengini bilme } \\
\text { durumu }\end{array}$ & 82 & 47 & 43 & 51 & 223 & $\begin{array}{l}\chi_{(0,05 ; s d=3)}^{2} \\
=17,054 \\
p=0,001\end{array}$ \\
\hline $\begin{array}{l}\text { Tehlikeli atık torbasının rengini bilme } \\
\text { durumu }\end{array}$ & 29 & 24 & 23 & 34 & 110 & $\begin{array}{l}\chi_{(0,05 ; s d=3)}^{2} \\
=19,506 \\
p=0,000\end{array}$ \\
\hline Toplam öğrenci sayıları & 207 & 114 & 90 & 83 & 494 & \\
\hline
\end{tabular}

Tablo 4'te "Tıbbi atık yönetimiyle ilgili yeterli düzeyde bilgi sahibi olduğunuzu düşünüyor musunuz?" soruna evet cevabı verenlerin sınıfları arasında anlamlı farklılık olup olmadığını ortaya koyabilmek için yapılan tek örneklem ki kare testi sonuçları yer verilmiştir. Sınıflar arasında anlamlı bir fark olduğu ortaya çıkmıştır $\left(\chi_{(0,05 ; s d=3)}^{2}=14,161 ; p=0,003\right)$. Farkın hangi sınıftan kaynaklandığı otaya koyulabilmesi için 4 . sınıf çıkartılarak tekrar yapılan tek örneklem ki kare testi sonucunda $\left(\chi_{(0,05 ; s d=2)}^{2}=5,323 ; p=0,070\right)$ diğer sinıflar arasında anlamlı bir farklilik bulunamamıştır. 4. sınıf öğrencilerinden bu soruya evet diyenlerin oranı $(\% 68,67)$ göz önünde bulundurulduğunda tıbbi atık yönetimiyle alakalı öğrenciler, yeterli düzeyde bilgi sahibi olduklarını düşünmektedirler. 
Tablo 4'te "Tıbbi atıkların sınıflandırmasını biliyor musunuz?" soruna evet cevabı verenlerin sınıfları arasında anlamlı farklılık olup olmadığını ortaya koyabilmek için yapılan tek örneklem ki kare testi sonuçlarına yer verilmiştir. Sınıflar arasında anlamlı bir fark olduğu ortaya çıkmıştır $\quad\left(\chi_{(0,05 ; s d=2)}^{2}=30,254 ; \mathrm{p}=0,000\right)$. Farkın hangi sınıftan kaynaklandığı ortaya koyulabilmesi için sınıflar arasında tekrar tek örneklem ki kare testi yapılmıştır. 2. 3. ve 4. sınıfları $\left(\chi_{(0,05 ; s d=2)}^{2}=14,549 ; p=0,001\right)$ arasında anlamlı bir fark olduğu; 1 . ve 2 . siniflar $\left(\chi_{(0,05 ; s d=1)}^{2}=\right.$ $0,214 ; p=0,644)$ ile 3 . ve 4 . siniflar $\left(\chi_{(0,05 ; s d=1)}^{2}=1,798 ; p=0,180\right)$ arasinda yapilan tek örneklem ki kare testinde anlamlı bir farkın olmadığı tespit edilmiştir. 3. ve 4. sınıflardan bu soruya evet diyenlerin oranı $(\% 64,44$ ve \%81,92) göz önünde bulundurulduğunda tıbbi atıkların sınıflandırmasını diğerlerine göre daha fazla bilgi sahibi oldukları düşünülmektedir.

Tablo 4'te "Tıbbi atık toplama torbalarının renklerini biliyor musunuz?" soruna evet cevabı verenlerin sınıfları arasında anlamlı farklılık olup olmadığını ortaya koyabilmek için yapılan tek örneklem ki kare testi sonuçlarına yer verilmiştir. Sınıflar arasında anlamlı bir fark olduğu ortaya çıkmışırı $\left(\chi_{(0,05 ; s d=3)}^{2}=25,184 ; p<0,001\right)$. Farkın hangi sınıftan kaynaklandığı ortaya koyulabilmesi için sınıflar arasında tekrar tek örneklem ki kare testi yapılmıştır. 2. 3. ve 4. sinıfları $\left(\chi_{(0,05 ; s d=2)}^{2}=8,194 ; p=0,017\right)$ arasında yapılan tek örneklem ki kare testinde anlamlı bir fark olduğu; 1. ve 2. sinıflar $\left(\chi_{(0,05 ; s d=1)}^{2}=2,103 ; p=0,147\right)$ ile 3. ve 4. $\sin 1$ flar $\left(\chi_{(0,05 ; s d=1)}^{2}=1,594\right.$; $p=0,207)$ arasında yapılan tek örneklem ki kare testinde anlamlı bir farkın olmadığı tespit edilmiştir. 3. ve 4. sınıflardan bu soruya evet diyenlerin oranı $(\% 61,11$ ve $\% 77,10)$ göz önünde bulundurulduğunda tıbbi atık toplama torba renklerini diğerlerine göre daha fazla bilgi sahibi oldukları düşünülmektedir.

Tablo 4'te "Biyotehlike simgesini bilme durumu" sorusunu bilenlerin sinifları arasinda anlamlı farklılık olup olmadığını ortaya koyabilmek için yapılan tek örneklem ki kare testi sonuçlarına yer verilmiştir. 1. 2. 3. ve 4. sınıflar arasında yapılan tek örneklem ki kare testinde anlamlı bir farkın olmadığı $\left(\chi_{(0,05 ; s d=3)}^{2}=5,222 ; p=0,156\right)$ tespit edilmiştir. 1. 2. 3. ve 4 . sinıflarından bu soruyu bilenlerin oranı (\%53,14; \%56,14; \%73,33 ve \%65,06) göz önünde bulundurulduğunda biyotehlike simgesini genel olarak bildiği düşünülmektedir.

Tablo 4'te "Evsel atık torbasının rengini bilme durumu" sorusunu bilenlerin sinifları arasında anlamlı farklılık olup olmadığını ortaya koyabilmek için yapılan tek örneklem ki kare testi sonuçlarına yer verilmiştir. 1. 2. 3. ve 4. sınıflar arasında yapılan tek örneklem ki kare testinde anlamlı bir farkın olduğu $\left(\chi_{(0,05 ; s d=3)}^{2}=14,829 ; p=0,002\right)$ ortaya çıkmıştır. Farkın hangi sınıftan kaynaklandığı ortaya koyulabilmesi için sınıflar arasında tekrar ki kare testi yapılmıştır. 1 . 2. ve 3. $\sin ı f l a r\left(\chi_{(0,05 ; s d=1)}^{2}=3,241 ; p=0,198\right)$ arasinda yapılan tek örneklem ki kare testinde anlamlı bir farkın olmadığı tespit edilmiştir. 4. sınıf öğrencilerinden bu soruyu bilenlerin oranı $(\% 66,26)$ göz önünde bulundurulduğunda öğrencilerin evsel atık torbasının rengi konusunda bilgi sahibi olduklarını düşünmektedirler.

Tablo 4'te "T1bbi atık torbasının rengini bilme durumu" sorusunu bilenlerin sinıfları arasında anlamlı farklılık olup olmadığını ortaya koyabilmek için yapılan tek örneklem ki kare testi sonuçlarına yer verilmiştir. 1. 2. 3. ve 4. sınıflar arasında yapılan tek örneklem ki kare testinde anlamlı bir farkın olduğu $\left(\chi_{(0,05 ; s d=3)}^{2}=26,764 ; p=0,000\right)$ ortaya çıkmıştır. Farkın hangi sınıftan kaynaklandığı ortaya koyulabilmesi için sınıflar arasında tekrar ki kare testi yapılmıştır. 1. 2. ve 3 . sinıflar arasında yapılan tek örneklem ki kare testinde anlamlı bir farkın olduğu $\left(\chi_{(0,05 ; s d=3)}^{2}=\right.$ $7,933 ; p=0,019)$ ortaya çıkmıştır. 1 . ve 2 . sınıflar arasında yapılan tek örneklem ki kare testinde anlamlı bir farkın olmadığı $\left(\chi_{(0,05 ; s d=3)}^{2}=1,672 ; p=0,196\right)$ tespit edilmiştir. 3. ve 4. sınıflardan bu soruyu bilenlerin oranları $(\% 57,77$ ve $\% 79,51)$ göz önünde bulundurulduğunda tıbbi atık torbasının rengini konusunda diğerlerine göre daha fazla bilgi sahibi oldukları düşünülmektedir. 
Tablo 4'te "Geri dönüşüm atık torbasının rengini bilme durumu" sorusunu bilenlerin sınıfları arasında anlamlı farklılık olup olmadığını ortaya koyabilmek için yapılan tek örneklem ki kare testi sonuçlarına yer verilmiştir. 1. 2. 3. ve 4. sınıflar arasında yapılan tek örneklem ki kare testinde anlamlı bir farkın olduğu $\left(\chi_{(0,05 ; s d=3)}^{2}=17,054 ; p=0,001\right)$ ortaya çıkmıştır. Farkın hangi sınıftan kaynaklandığı ortaya koyulabilmesi için sınıflar arasında tekrar tek örneklem ki kare testi yapılmıştır. 1. 2. ve 3. sınıflar $\left(\chi_{(0,05 ; s d=2)}^{2}=2,248 ; p=0,325\right)$ arasında yapılan tek örneklem ki kare testinde anlamlı bir farkın olmadığı tespit edilmiştir. 4. sınıf öğrencilerinden bu soruyu bilenlerin oranı $(\% 61,44)$ göz önünde bulundurulduğunda öğrencilerin evsel atık torbasının rengi konusunda bilgi sahibi oldukları düşünülmektedirler.

Tablo 4'te "Tehlikeli atık torbasının rengini bilme durumu" sorusunu bilenlerin sinıfları arasında anlamlı farklılık olup olmadığını ortaya koyabilmek için yapılan tek örneklem ki kare testi sonuçlarına yer verilmiştir. 1. 2. 3. ve 4. sınıflar arasında yapılan tek örneklem ki kare testinde anlamlı bir farkın olduğu $\left(\chi_{(0,05 ; s d=3)}^{2}=19,506 p=0,000\right)$ ortaya çıkmıştır. Farkın hangi sınıftan kaynaklandığı ortaya koyulabilmesi için sınıflar arasında tekrar tek örneklem ki kare testi yapılmıştır. 1. 2. ve 3. sınıflar arasında yapılan tek örneklem ki kare testinde anlamlı bir farkın olmadığ $\left(\chi_{(0,05 ; s d=3)}^{2}=4,838 p=0,089\right)$ tespit edilmiş̧ir. 4. sınıf öğrencilerinden bu soruyu bilenlerin oranı $(\% 40,96)$ göz önünde bulundurulduğunda öğrencilerin tehlikeli atık torbasının rengi konusunda orta düzeyde bilgi sahibi oldukları düşünülmektedirler.

\section{Tartışma ve Sonuç}

Çalışma ile sağlık bilimleri fakültesi öğrencilerinin özellikle tıbbi atık miktarının fazla olduğu COVID-19 pandemi sürecinde tıbbi atık yönetimine ilişkin bilgi düzeylerinin, tutum ve davranışlarının değerlendirilmesi amaçlanmaktadır. Buna ek olarak atık yönetimi ile ilgili farkındalık kazanmaları adına sonraki dönemlerde atık yönetimi ile ilgili eğitimler verilmesine ne kadar ihtiyaç olduğu sorusuna da cevap bulunmuş olacaktır.

Köseoğlu, Toptan ve Altındiş (2019) çalışmalarında diş hekimlerinin \%68'den fazlasının tıbbi atık torba renklerini bildikleri, çalış1lan kurumlarda atıkları ayrı ayrı torbalara attıkları, tıbbi atık yönetimi ile ilgili ders aldıkları ve $\% 81,23$ 'ünün biyotehlike simgesini bildikleri tespit edilmiştir. Bu çalışmada ise $\% 48,4$ 'ünün tıbbi atık torbasını rengini bildiğii çalışmaya katılanların \%34,4'ünün tıbbi atık yönetimi ile ilgili ders aldıkları; \%59,05'inin biyotehlike simgesini bildikleri saptanmıştır. Tıbbi atık yönetimi ile ilgili sağlık bilimleri fakültesi öğrencilerinin ortalamalarının düşük olduğu dikkat çekse de hem diş hekimlerinin hem de öğrencilerin atık yönetimi ile ilgili bilgi düzeylerinin artırılması, tutum ve davranışlarının değiştirilerek farkındalık oluşturulması için eğitime ihtiyaçlarının olduğu sonucuna varılmıştır.

Terzi ve Yüce (2017) çalışmalarında sağlık hizmet meslek yüksekokulu son sınıf öğrencilerinin \%70,7'sinin tıbbi atık yönetimi ile ilgili bir ders aldıkları; \%39,8'inin tıbbi atık sınıflandırmasını bildikleri; \%79'unun tıbbi atık toplama rengini bildikleri tespit edilmiştir. $\mathrm{Bu}$ çalışmada ise sağlık bilimleri fakültesi öğrencilerinin \%34,4'ünün tıbbi atık yönetimi ile ilgili ders aldıkları; \%48,4'ünün tıbbi atık toplama rengini bildikleri tespit edilmiştir. Her iki çalışmada da öğrencilerin atık yönetimi ile ilgili bilgi düzeylerinin yeterli olmadığı ve eğitime ihtiyaçlarının olduğu düşünülmektedir.

Malini ve Eshwar (2015) çalışmalarında hemşirelerin yarıdan azının atıkların renk kodlarını bildiği; doktor ve hemşirelerin \%50'sinin laboratuvar teknisyenlerinin \%26'sının tıbbi atık yönetimi ile ilgili ders aldıkları tespit edilmişken bu çalışmada \%48,4'ünün tıbbi atık toplama rengini bildikleri; \%34,4'ünün tıbbi atık yönetimi ile ilgili ders aldıkları tespit edilmiştir. Sağlık çalışanlarıyla ilgili çalışmada bazı çalışanların hiç eğitim almadıkları dikkat çeken bir detay olarak karşımıza çıkmaktadır. Bu bağlamda ele alındığında hem sağlık çalışmalarının hem de öğrencilerin eğitime ihtiyaçlarının olduğu sonucuna varılmıştır. 
Jadhav, Thangaraj, Dsouza ve Rao (2015) çalışmalarında öğrencilerin tıbbi atıkla ilgili eğitim düzeylerinin yüksek olduğu almış oldukları eğitimlerin bilgi, tutum ve uygulamalarında iyileşmelere sebep olduğu vurgulanmıştır. Bu çalışmada öğrencilerin bilgi düzeyleri istenilen düzeyde çıkmamıştır. Öğrencilerin bilgi düzeylerinde, tutum ve davranışlarında iyileştirmelerin olmasi için eğitim verilmesine ihtiyaç duyulduğu saptanmıştır.

Ujwala U, Ramasankaram, Satyanarayan, Appajirao, Kulkarni (2012) çalışmalarında tıp ve sağlık öğrencilerinin yarısının tıbbi atık torba renklerini bildiği tespit edilmişken bu çalışmada sağlık bilimleri fakültesi öğrencilerinin neredeyse yarısının tıbbi atık torba renklerini bildikleri ortaya çıkmıştır. İki çalışma için de öğrencilerin tıbbi atık yönetimi konularında eğitime ihtiyaçlarının olduğu düşünülmektedir.

Mathur, Dwivedi, Hassan ve Misra (2011) çalışmalarında sağlık çalışanlarının tıbbi atık yönetimi ile ilgili bilgi düzeylerinin meslekleri baz alındığında değişiklik gösterdiği tespit edilmiştir. Bu çalışmada da bölüm baz alındığında tıbbi atık eğitimlerinden kaynaklı olarak farkl1lıkların olduğu düşünülmektedir. Özellikle Hemşirelik ve Sağlık Yönetimi bölümlerinin üçüncü ve dördüncü sınıf öğrencilerinden tıbbi atık konusunun yer aldığı ders sayıları göz önünde bulundurulduğunda bilgi düzeylerinin beklenilen şekliyle daha yüksek olduğu yapılan tek örneklem ki kare testi ile ortaya koyulmuştur. İki çalışma içinde meslekler ve bölümler arasında farklılıkların olması tıbbi atık yönetimi ile ilgili derslerin sayısının artırılmasının çalışanların ve öğrencilerin bilgi düzeyleri, tutum ve davranışlarında iyileştirmelere sebep olduğu düşünülmektedir.

Sağlık bilimleri öğrencileri hem eğitimleri esnasında hem de çalışma hayatlarında tıbbi atıklardan kaynaklı potansiyel risk altında oldukları bilinmektedir (Ujwala vd., 2015: 248). Tibbi atıkların toplaması ve bertaraf edilmesi konularında sağlı çalışanlarının ve sağlıkla ilgili bölümlerde eğitim öğretim faaliyetlerinde bulunan öğrencilerin daha bilinçli olmaları beklenmektedir. Bu çalışmada da özellikle hemşirelik ve sağlık yönetimi üçüncü ve dördüncü sınıf öğrencilerinin tıbbi atık yönetimi konularında daha dikkatli oldukları gözlemlenmiştir.

Sağlık kuruluşlarında tıbbi atıkların yönetimiyle ilgili mevzuatlarla sınırlar çizilmiş olsa da sağlık çalışanlarının bu konudaki bilgi ve farkındalıklarının yeterli düzeyde olmadığ çalışmalarda bildirilmektedir (Malini \& Eshwar, 2015: 172; Mathur vd., 2011: 143 ). İlgili literatürde öğrencilerin eğitim düzeyleri arttıkça bilgi, tutum ve farkındalıklarının arttığı ifade edilmektedir (Jadhav vd., 2015: 726),

Tıbbi atık konusunda daha bilinçli olmaları ve toplum içerisinde örnek davranışlar sergilemeleri beklenen sağlıkçı adaylarının tıbbi atık yönetimi ile ilgili bilgi düzeylerinin yeterli olmadığı sonucuna varılmıştır. Bu yüzden özellikle hastanede aktif rollerde bulunacak olan sağlık profesyoneli adayı olan öğrencilerin tıbbi atık yönetimi ile ilgili bilgi düzeylerinin artırılması için ilgili derslerde tıbbi atık yönetimi konusu üzerinde daha fazla durulması gerekmektedir. Bu durum tıbbi atık yönetimi ile ilgili öğrencilerin bilgi, tutum ve davranışlarını olumlu yönde etkileyecektir.

Çalışmada sağlık bilimleri öğrencilerinin tıbbi atık yönetimi hakkında bilgi düzeyleri araştırılıp, konu ile alakalı eğitimler verilerek sonraki dönemlerde benzer örneklemlerde çalışmanın tekrarlanarak anlamlı bir farklılık olup olmadığının ortaya konulması sonraki çalışmalar için önerilmektedir. Diğer bir öneri ise; hastanede uygulamalı eğitimlerde öğrencilerin tıbbi atıklarla ilgili ilgili mevzuatları da içeren uygulamalı eğitimlerin verilmesidir. $\mathrm{Bu}$ eğitimler öğrencilerin tıbbi atıklarla ilgili bilinçlenmelerini sağlayacak ve bilgi düzeylerini artıracaktır.

\section{Kaynakça}

Akbolat M, Işık O., Dede, C. \& Çimen M. (2011). Sağlık Çalışanlarının Tibbi Atık Bilgi Düzeylerinin Değerlendirilmesi. Acıbadem Üniversitesi Sağllk Bilimleri Dergisi, 2(3),131140. 
COVID-19 Salgın Yönetimi ve Çalışma Rehberi, (2021). Bilimsel Danışma Kurulu Çalışması. Erişim Tarihi: 20 Temmuz 2021. https://covid19.saglik.gov.tr/Eklenti/40982/0/covid19toplumdasalginyonetimirehberipdf.pdf

Doğan P. \& Aktaş, S. (2017). Hemşirelik Öğrencilerinin Hastane Atıklarının Yönetimine İlişkin Bilgi Düzeyleri. Kocatepe Tup Dergisi, 18(3), 94-99.

Halk Sağlı̆̆ı Uzmanları Dernĕgi. COVID-19 Pandemisinde Atık Yönetimi. Erişim Tarihi: 25 Ocak 2021, https://korona.hasuder.org.tr/covid-19-pandemisinde-atik-yonetimi/.

Jadhav, J. Thangaraj, S. Dsouza, L. \& Rao, A. (2015). Assessment of educational intervention on biomedical waste management among Government Nursing College students, Bengaluru. International Journal of Medical Science and Public Health. 4(5), 726-729.

Köseoğlu, M. Toptan, H. \& Altındiş, S. (2019). Diş Hekimlerinin Tıbbi Atık Yönetimi Konusundaki Bilgi, Tutum ve Davranışlarının Araştırılması. Sakarya Tıp Dergisi. 9(2), 245-252.

Malini, A. \& Eshwar, B. (2015). Knowledge, Attitude and Practice of Biomedical waste management among health care personnel in a tertiary care hospital in Puducherry. International Journal of Biomedical Research. 6(03), 172-176.

Mathur, V. Dwivedi, S. Hassan, M.A. \& Misra, R.P. Knowledge, attitude, and practices about biomedical waste management among healthcare personnel: A cross-sectional study. Indian J Community Med. 36 (2011): 143-145.

South China Morning Post. Coronavirus leaves China with mountains of medical waste. Erişim Tarihi: 24 Ocak 2021, https://www.scmp.com/news/china/society/article/3074722/coronavirus-leaves-chinamountains-medical-waste.

Terzi, Ö. \& Yüce, M. (2017). Bir Hastanedeki Stajyer Öğrencilerin Tıbbi Atık Yönetimi Konusundaki Bilgi Düzeylerinin Değerlendirilmesi. Gümüşhane Üniversitesi Să̆llk Bilimleri Dergisi. 6(1), 58-64.

Turan, N., Özdemir Aydın, G., Kaya, H., Atabek Aştı, T. A., Aksel, G. \& Yılmaz, A. (2019). Hemşirelik Öğrencilerinin Tıbbi Atık Yönetimine İlişkin Bilgi Düzeyleri. Ordu Üniversitesi Hemşirelik Çalışmaları Dergisi, 2(1), 11-21.

Ujwala U, U., Ramasankaram, K., Satyanarayan, D., Appajirao, N. N. \& Ved P. Kulkarni (2012). Awareness about biomedical waste management in undergraduate medical and nursing students at a Teaching Institute in Vizianagaram, Andhra Pradesh. National Journal of Community Medicine, 3(3), 428-432.

UNEP - UN Environment Programme. Waste management an essential public service in the fight to beat COVID-19. Erişim Tarihi: 24 Ocak 2021, http://www.unep.org/news-andstories/press-release/waste-management-essential-public-service-fight-beat-covid-19.

\section{Beyan ve Açılamalar (Disclosure Statements)}

1. Araştırmacıların katkı oranı beyanı / Contribution rate statement of researchers:

Yazar/First author \%51, Yazar/Second author \%49.

2. Yazarlar tarafından herhangi bir çıkar çatışması beyan edilmemiştir (No potential conflict of interest was reported by the authors). 